\title{
Creating a Virtual Science Lab (VSL): the adoption of virtual labs in Saudi schools
}

\author{
Khulood Aljuhani ${ }^{1 *}$, Marwa Sonbul' ${ }^{2}$, Mashail Althabiti ${ }^{2}$ and Maram Meccawy ${ }^{2}$
}

\author{
* Correspondence: kmehiyawi@ \\ taibahu.edu.sa \\ ${ }^{1}$ Information Systems Department, \\ Faculty of Science and Computer \\ Engineering, Taibah University, \\ Yanbu, Saudi Arabia \\ Full list of author information is \\ available at the end of the article
}

\begin{abstract}
Laboratory activities are playing a substantial role in supporting scientific learning fields by enabling students to obtain practical skills through experiments and by giving them the chance to have a more profound understanding of the content. Although laboratory activities are expensive and time-consuming, virtual laboratory activities can save money, time, and effort. The Virtual Science Lab (VSL) is a web-based platform designed to improve learning approaches by introducing a safe and interactive lab environment for students in middle schools in Saudi Arabia. VSL was found to be an exciting, useful, and enjoyable learning environment during user trials. It allowed users to conduct experiments individually and to repeat them multiple times if needed.

Keywords: Virtual laboratory, Online science lab, Virtual online education, Edu tech, Emerging technology
\end{abstract}

\section{Introduction}

We live in an era of rapidly developing technology due to the widespread use of computer science and information technology, which have entered almost all areas of life. In the field of education, emerging technologies provide opportunities for enhancing and improving the learning and education process and using technological tools effectively in the teaching process will help change learning and communication methods (Meccawy 2017). For example, the artificial educational environment uses computers to simulate reality. Over the past two decades, the application of artificial educational situations has resulted in a change in the educational process for students and teachers and has been confirmed to be effective for teaching complex science topics (Babateen 2011).

What differentiates science from other subjects is that it is an empirical field that involves conducting experiments in science laboratories. A laboratory equipped with modern equipment increases students' motivation to learn and enhances the teaching process (Ayesh 2004). Virtual labs are a type of technology that needs be brought into classrooms to enhance current learning methods (Kennepohl 2011). The teaching of science in Saudi Arabia has many barriers that affect teaching activities and reduce students' inventive skills, such as the limited time of science lessons, teachers' schedules and the large number of students in the laboratory, which leads to their inability to follow up on the experiment.

(c) The Author(s). 2018 Open Access This article is distributed under the terms of the Creative Commons Attribution 4.0 International License (http://creativecommons.org/licenses/by/4.0/), which permits unrestricted use, distribution, and reproduction in any medium, provided you give appropriate credit to the original author(s) and the source, provide a link to the Creative Commons license, and indicate if changes were made. 
In this paper, a virtual lab has been developed as an alternative to the science labs in the middle schools in Saudi Arabia to enhance the science teaching process. The Virtual Science Lab (VSL) is a web-based system designed in Arabic to help students conduct laboratory experiments in a safe and interactive manner. The system also allows science teachers to set laboratory tests and evaluate their students' performance.

The motivation for Virtual Science lab was the observed limitations of existing learning environments concerning science subjects' laboratories in Saudi Arabian schools. This study argues that technology could be used innovatively to fill this gap and address those limitations. The result would be a learning environment for laboratory experiments that reforms of the ways of teaching and learning science. Learners get to interact with this environment that cater for their needs and provides adequate support through feedback.

The remainder of this paper is arranged as follows: the second section provides background and a review of the research concerning virtual science labs. The third section and fourth sections present the virtual science lab system in further details, including the understanding the research issue and design phases. The fifth section shows the results of the testing phase and is followed by the discussion and conclusion, which are presented in sections six and seven, respectively. Finally, the limitation of the research is discussed in the eighth section.

\section{Related works}

The use of technology in education plays an essential role in enhancing the learning process and increasing its effectiveness. It helps teachers explain and present information efficiently in an enjoyable way and helps students collaborate with their teachers, access other educational resources, and learn technical skills. The VSL is an educational environment that uses virtual technology and provides tools and visualizations that motivate the students to participate and collaborate within the class. It is a good alternative for schools that cannot build labs and provide tools and equipment.

Furthermore, it is one of the most important applications of computer simulations used for science learning (Babateen 2011). It has been defined as "a laboratory experiment programmed, using the computer for simulating the operations in the real laboratory, which helps students to link easily between the theoretical and practical aspects" (Keller and Keller 2005, p.5). It has also been defined as "software-tools; that allow users to design repeated experiments to test the effects of variables" (Toth 2016, P.158). In the VSL, students can collect real data from remotely controlled instruments and explore them using simulated ones, such as the virtual microscope that uses high-resolution images instead of actual specimens (Waldrop 2013).

The activities in both virtual laboratories (VLs) and hands-on laboratories (HOLs) can enhance the learning environment and make it more constructive. However, there are differences between them related to the nature of students' learning situations, for example, the students in HOLs focus on how to use the physical equipment and the outcomes, while VLs direct students' attention to variables and the interaction of the variables that produce the outcomes (Toth 2016; Widodo et al. 2017).

The importance of using VLs in science education lies in the fact that they offer the best solution for conducting laboratory activities as the students can perform lab activities using computer software, which is cheaper and more efficient. Furthermore, VLs allow students to repeat an experiment many times without any risk of danger. Also, VLs help 
students examine anomalous data that do not concur with prior knowledge, theories, and expectations. Such data are hard to investigate in HOLs (Widodo et al. 2017). In addition, using computational platforms in VLs provides easy to access and portable analyses and the flexible user interfaces meet various user needs and expectations (Afgan et al. 2015). Indeed, students who are taught using VLs often perform better than those who learn in HOLs (Falode and Onasanya 2015).

In Greece, the lack of resources and time needed to construct labs in secondary schools has been solved by using a web-based platform that simulates real labs (Alexiou et al. 2005). This platform allows students to conduct difficult experiments that cannot take place in real labs. Moreover, VLs have had a positive impact on students and their performance and their effectiveness has been shown in many research studies. One such study tested the students' achievements using 16 virtual chemistry experiments and found that using the virtual environment increased the students' interest in chemistry and improved their understanding of the subject (Tuysuz 2010). In addition, elementary school students who used VLs achieved a better understanding and higher grades than those who used HOLs (Sun et al. 2008).

VLs can also be used to train students before they conduct hands-on experiments in real labs (Bortnik et al. 2017). The authors have studied how chemistry VLs affected student achievement level. They measured achievement in two environments: a hands-on environment (traditional) and a blended environment (combination of hands-on and virtual learning). It was found that the students in the blended environment were more engaged and performing better than the other group. Therefore, the authors recommended using VLs as a supplementary tool to improve students' studying and research skills.

VLs have also been used successfully in specialized sciences, such as biology, engineering, computing, etc. An excellent example of using VLs in the pedagogical approach is MyDNA VSL. This is used for developing the concept and process of DNA fragment separation within the biomedical topic of the 'Cellular Machinery' course, which is taught at an engineering faculty in a large research university in the United States. With MyDNA VSL, students can efficiently run repeated experiments and study the effects of different variables (Toth 2016).

Another example of VLs being used efficiently is SensorDB, which is a web-based sensor that uses a state-of-the-art cloud to gather, analyze, and visualize data. This VL can manage large volumes of biological time series sensor data in five stages of data queries through real-time user interaction. SensorDB also supports powerful stream data processing tools, such as "do it yourself," which enables users to manipulate their data without the need for rapid programming. Furthermore, SensorDB allows the adoption of various applications without having to directly interact with the core development team, which empowers the community of users (Salehi et al. 2015).

When observing the state of science education in Saudi Arabia today, critical issues can be seen, such as the lack of laboratory equipment and the funding needed to provide materials for each student, and the risks associated with carrying out some scientific experiments. These issues mean that students tend to gain knowledge through theoretical methods and rarely use their knowledge practically (Babateen 2011). Furthermore, students cannot conduct experiments due to restricted lab space, which forces them to only view trials instead of performing them. In summary, students cannot conduct scientific experiments in a practical, enjoyable, and safe manner, therefore, Saudi schools need an 
alternative lab environment that helps students combine the theoretical aspects with the practical ones, which is the aim of this paper.

Regarding Arabic VLs, there are some well-known ones, such as crocodile virtual lab (MGD), which is a web-based platform that provides experiments in Physics and Chemistry for different grades. The effect of crocodile on student skills was studied using a sample of 42 students from a secondary school in Riyadh. The students were split into two groups: the first one used the crocodile virtual lab and the second group used the real lab. The results showed that the students in the first group performed better in the post-test and could hypothesize about and interpret the data (Alshahry 2016). However, Crocodile VL has some limitations as it does not provide the experiences in the student's textbooks. Also, teachers cannot track the student's performance and communicate with them.

There is still a need for VLs that contain all the experiments found in school books. In this paper, the researchers examine the need for virtual science labs in middle schools in Saudi Arabia and propose a learning environment that enables students to conduct experiments and communicate with and access other relevant resources.

All these studies, exposed several complications in performing the scientific experiments flexibly; so the authors come up with the following questions: How to facilitate the education of science in Saudi Arabia and make it more enjoyable? How to reduce the science laboratories' budget? How can the science education in Saudi Arabia be in line with the developing technology?

\section{Understanding the research issue}

For a better understanding of the research problem, information was gathered from a target sample. Qualitative and Quantitative research methods were employed in this study to collect data related to real and virtual science labs in Saudi Arabian schools. Questionnaires and individual interviews were used to collect data from the sample, which included students, teachers, experts in science education, and parents of students in the Saudi middle schools.

The purpose of using the questionnaire is (a) to identify the state of the science labs in public education Saudi Arabian schools; (b) to measure your knowledge of virtual labs and their impact on the educational science process; (c) reach more participants from the targeted sample; (d) to collect information for better understanding of the research problem and establish the system requirements. Moreover, the interviews have been used to directly communicate with teachers and take an overview of the science education environment in schools in Saudi Arabia.

\section{Questionnaire}

The questionnaire was designed and distributed electronically through Google forums to reach participants of the target sample (see Additional file 1). The questions were written in Arabic, which is the native language of the participants, and were divided into three parts to make it clear and easy to be analyzed. These three parts were personal information, an evaluation of the current state of science labs in Saudi schools, and the effect of using VLs in science education from the participant's perspective. Three hundred and fifty-nine responses were received from various cities across Saudi Arabia. Sixty-eight 
percent of the participants were science teachers, $14.2 \%$ were students, and $8.4 \%$ were parents.

The results from the second section of the questionnaire indicated that $88.3 \%$ of schools in Saudi Arabia have a science lab, with $41.9 \%$ of those labs having space and conditions that are only slightly appropriate for the number of students and $29.1 \%$ having space and conditions that were not appropriate at all for the number of students. Furthermore, 59.9\% of the participants sometimes used the school lab to do experiments and $20.3 \%$ said that they had never conducted a laboratory experiment in the school lab.

When asked about the issues that hinder the conducting of experiments in the school labs, the answers were varied. Seventy-three percent of the responses spoke about the lack of laboratory equipment and materials, $44.4 \%$ about the short lecture time, $42.5 \%$ about the large number of students in a class, and $33.8 \%$ about the length of the science curriculum.

In the last section, the questionnaire defined the virtual laboratory concept and their advantages to make sure that all participants have the same idea about the virtual laboratories and then they were asked about VLs. The results showed that only $17.9 \%$ had used a VL before, but $54.1 \%$ believed that employing VLs in science education would enhance the learning process and increase students' grades. When the participants were asked about the differences between virtual and real laboratories, 71.2\% spoke of the ability to perform risky experiments in a safe environment in VLs, while 49.2\% indicated the ability of students to re-conduct experiments remotely multiple times, $41.3 \%$ pointed to the synchronization between theoretical and empirical learning, and $31.6 \%$ suggested that the VL system could help teachers evaluate students' performances electronically and guide students in conducting experiments.

\section{Interviews}

To support the survey results, six structured interviews with selected science teachers in Saudi Arabia, but four of them did not cooperate because of either school policies or their time. However, two interviews were conducted: one in a public school in the city of Yanbu and the other in the Dar-Alfikr, which is a private school in Jeddah.

These interviews aimed to collect specific information about science education in Saudi schools from their work experience and examine the advantages and drawbacks of using VLs instead of the schools' HOLs. The results of the interviews were consistent with the responses to the questionnaire as both teachers confirmed that the time allotted to science lectures is an issue when conducting experiments in the laboratory, especially with a large number of students. Also, they spoke about how students' lack of knowledge regarding the risks associated with some chemical materials and how to deal with a fire or an explosion could cause them harm. Due to this, they strongly supported the idea of using the VSL in middle schools as it would be a safe alternative to the HOLs.

They also mentioned that the lack of technology and the loss of internet connectivity in schools could hinder the use of VLs, however, and the need for training programs to train teachers in how to deal with this type of lab. Moreover, both agreed that the frequent use of VLs might lead to a lack of real interactions with laboratory tools. 
The VSL will allow students to conduct experiments individually and frequently anytime, anywhere. It will also provide additional experiments in different science subjects to support the teaching of science subjects and students' understanding. Furthermore, it will enable teachers to set laboratory tests and monitor their students' performance.

\section{The proposed virtual science lab system}

The primary objective of creating the VSL was to facilitate science's educational process by moving the whole environment from reality to virtual. This transition includes replacing heavy equipment with graphical tools, which are easier and faster to move with drag and drop features. Also, the VSL needs technical support instead of a science technician. Furthermore, the VSL uses technical equipment, such as computers, internet components, and specialized software, which costs much less than the equipment used in HOLs.

The VSL is a web-based platform designed to introduce a safe and interactive lab environment to students in middle schools in Saudi Arabia. It creates a virtual learning space that enables students to conduct experiments individually or in groups interactively via the internet. It also facilitates the science teaching process by providing communication and cooperation tools for teachers and their students, much like any e-learning system. Furthermore, it allows teachers to add additional experiments to enhance their students' knowledge and to perform laboratory tests to observe the improvement of their students.

\section{System design}

The development process was chosen to evolve the VSL because it supports user interface design and explores specific software solutions (Sommerville 2010). The layered architecture pattern shown in Fig. 1 was selected to design the VSL system because it supports the incremental development of the prototype process.

The VSL system has two kinds of users: teachers, who coordinate the scientific learning process by adding new experiments to enhance student knowledge and create tests to monitor their students' performance, and students, who can perform various experiments and complete the available tests. Furthermore, the VSL provides an interactive and safe environment for students and their sciences teachers that is written in Arabic. This facilitates direct communication between students and teachers anywhere, anytime. To activate the VSL, the researchers suggest using ASP.net as a programming language and connecting it to a SQL database, as shown in Fig. 1.

\section{User Interface design}

The VSL's design depends on the science's curriculum in Saudi Arabian middle schools: using the same experiments and tools within the conditions simulated to the real ones.

The main components of the system are shown in Fig. 2. Through the home page, the user can find all the courses, experimental tutorials, and technical support. The teacher must log in to set a test, add an experiment, or manage the students' performance and grades. Students must also log in to access the experiments and view the tests and their grades. 


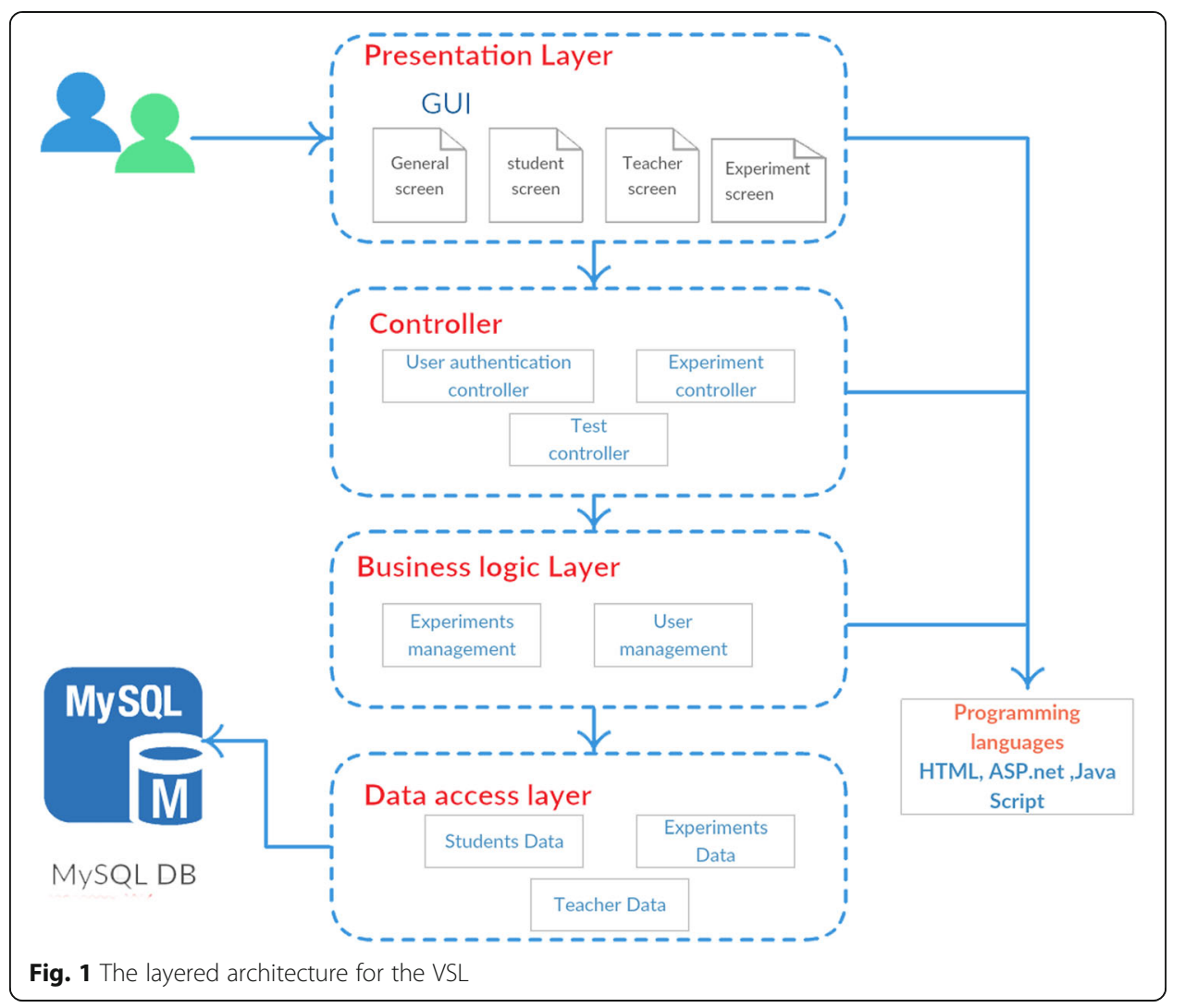

The system begins with the homepage screen (see Fig. 3), which contains the main four sections of the lab: courses, teachers, students, and experiment tutorials, with a separate screen for each. The courses screen provides an electronic copy of the science curriculum for all middle school levels. On the other hand, the experiment tutorial screen displays videos that have been uploaded to YouTube that may help students and teachers learn more about how to use the VSL platform to conduct experiments.

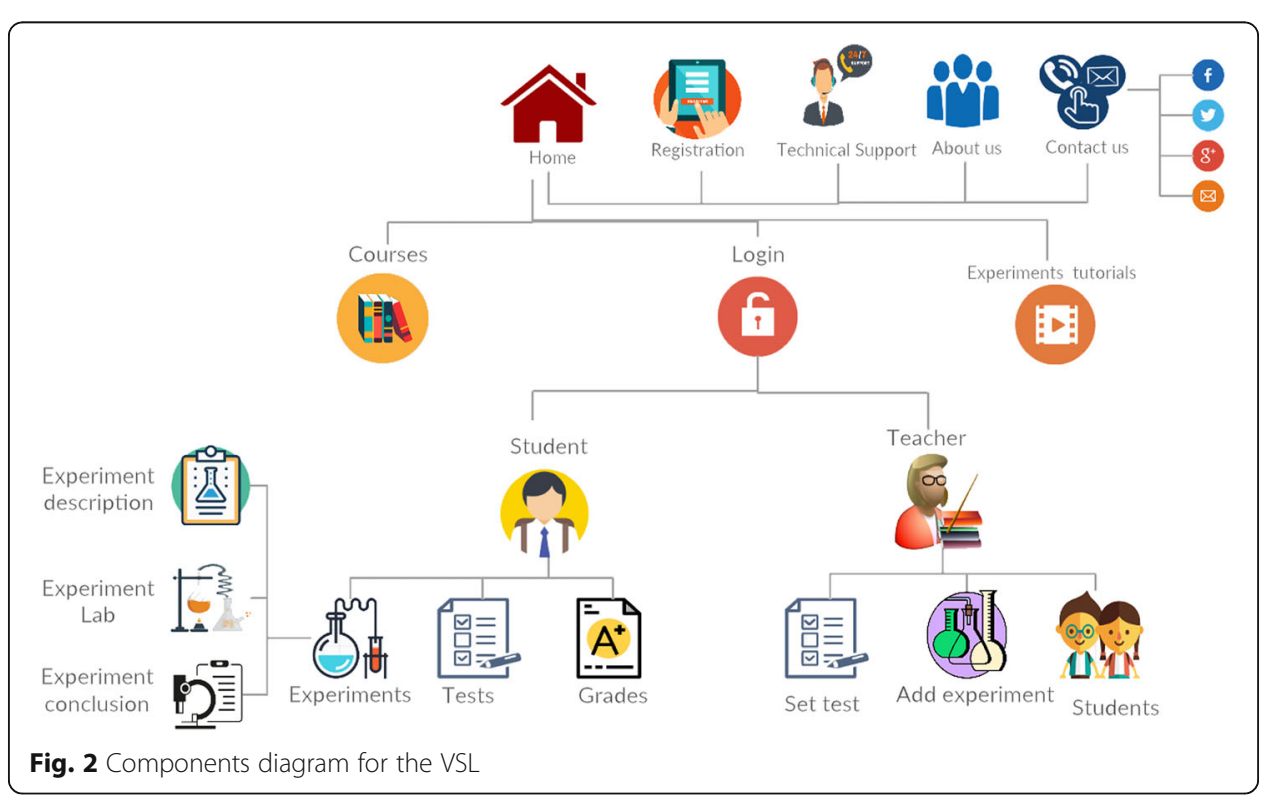




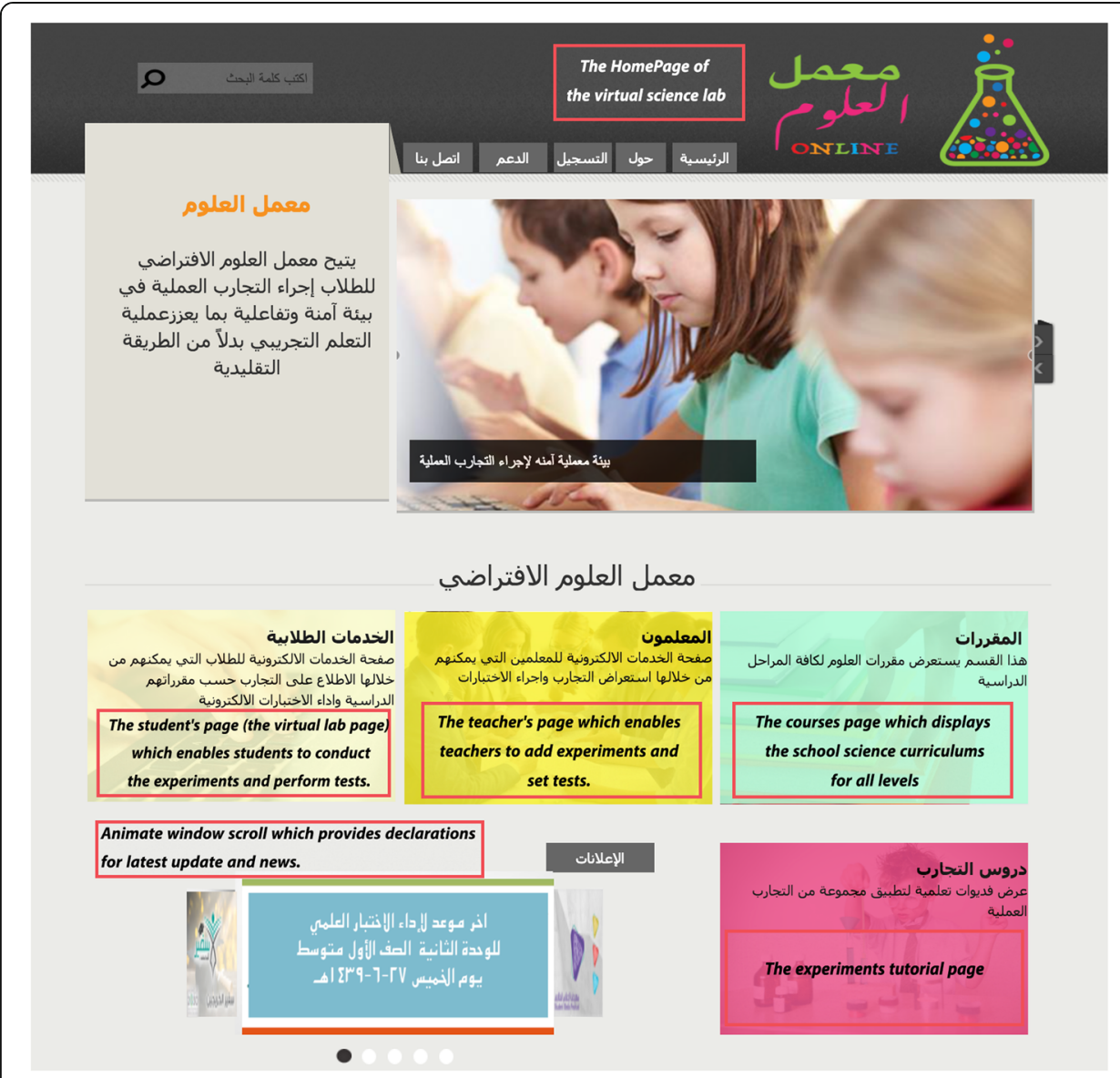

Fig. 3 Screenshot of the home screen of the VSL

The core of the VSL system is the student and teacher screens and registration must be completed to access these two screens. After completing the registration and signing in processes, the student screen (see Fig. 4) becomes available for students and enables them to access all the experiments relevant to their levels (stated during registration). Students can also view their schedule, tests, and grades that have been uploaded by the teacher. Before conducting an experiment, a page that contains the experiment's description and its objectives will appear.

Figure 5 shows the screen for an experiment. This screen has been designed to simulate the real laboratory environment where students need to find all the laboratory tools, materials, and steps to conduct the experiment; by selecting the materials, then dragging and dropping them into the beaker depending on the shown instructions. Therefore, if there are any hazardous or unknown tools, a warning message will appear. After that, the result of the experiment will be shown.

Then, the students can answer questions related to the results and the experiment's conclusion screen will then provide them with the experiment's outcome and allow them to re-conduct the experiment if they want to, and as much as they want.

The VSL system offers science teachers three significant functions that are shown on the teacher screen (see Fig. 6). The first function displays the data of students who are taught by the teacher and allows them to modify the grades and monitor the students' 


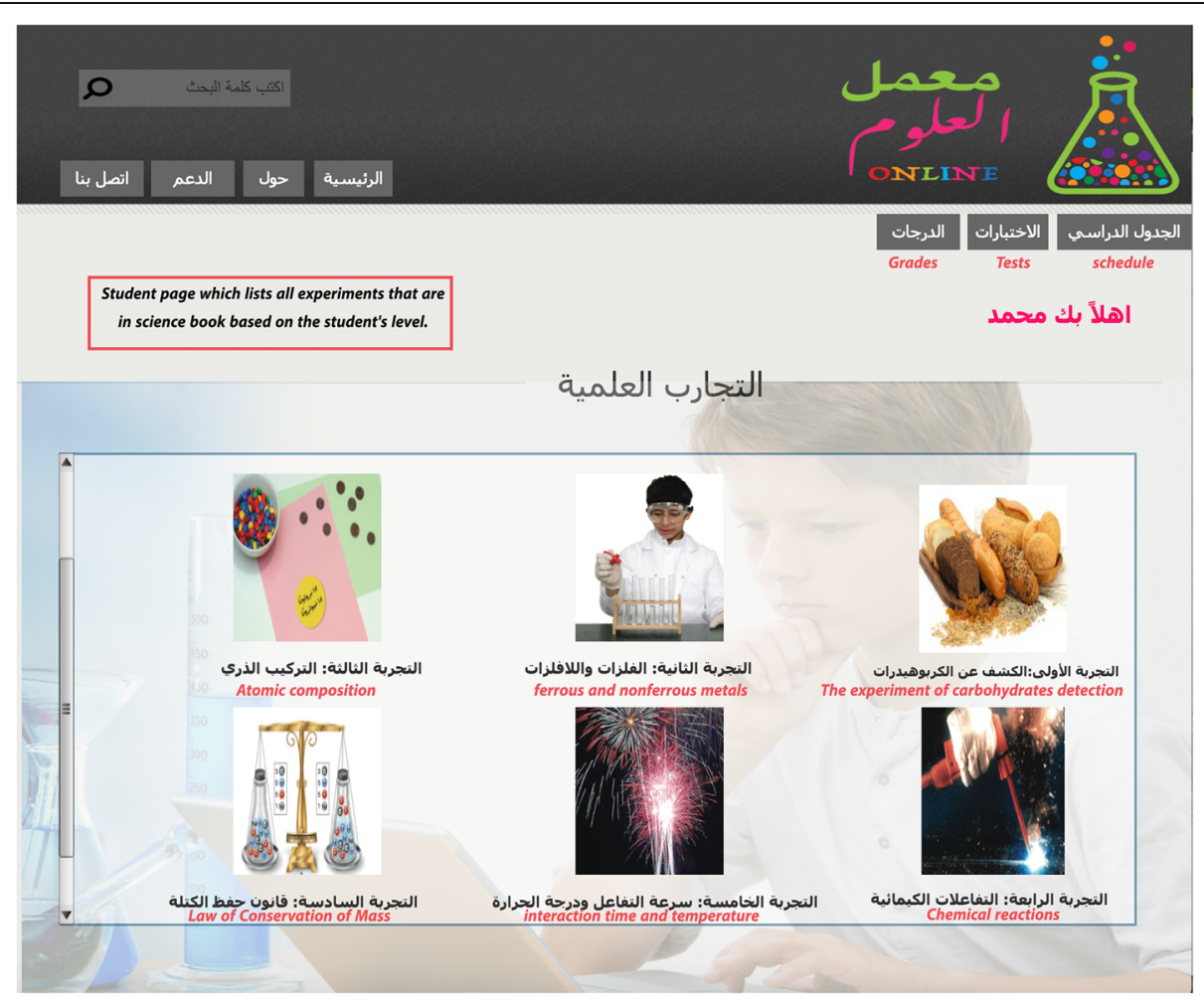

Fig. 4 Screenshot of the student screen on the VSL
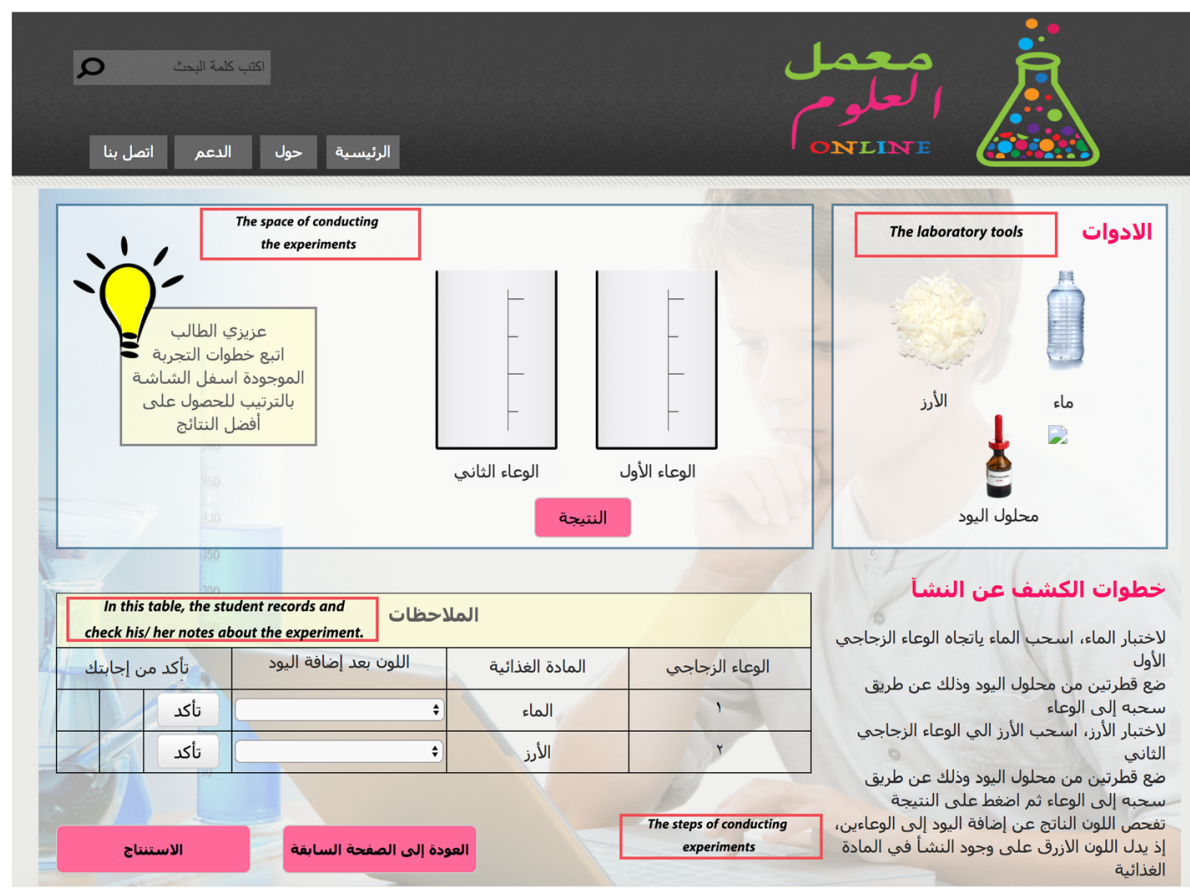

خطوات الكشف عن النشا

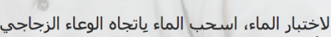
الأول

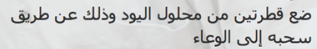

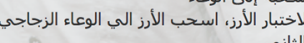

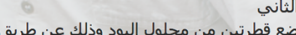

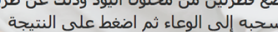
تفحص اللون الناتج عن اضافة اليود إلى الوعاءئين،

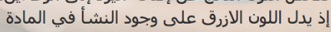

Fig. 5 Screenshot of an experiment's interface on the VSL 


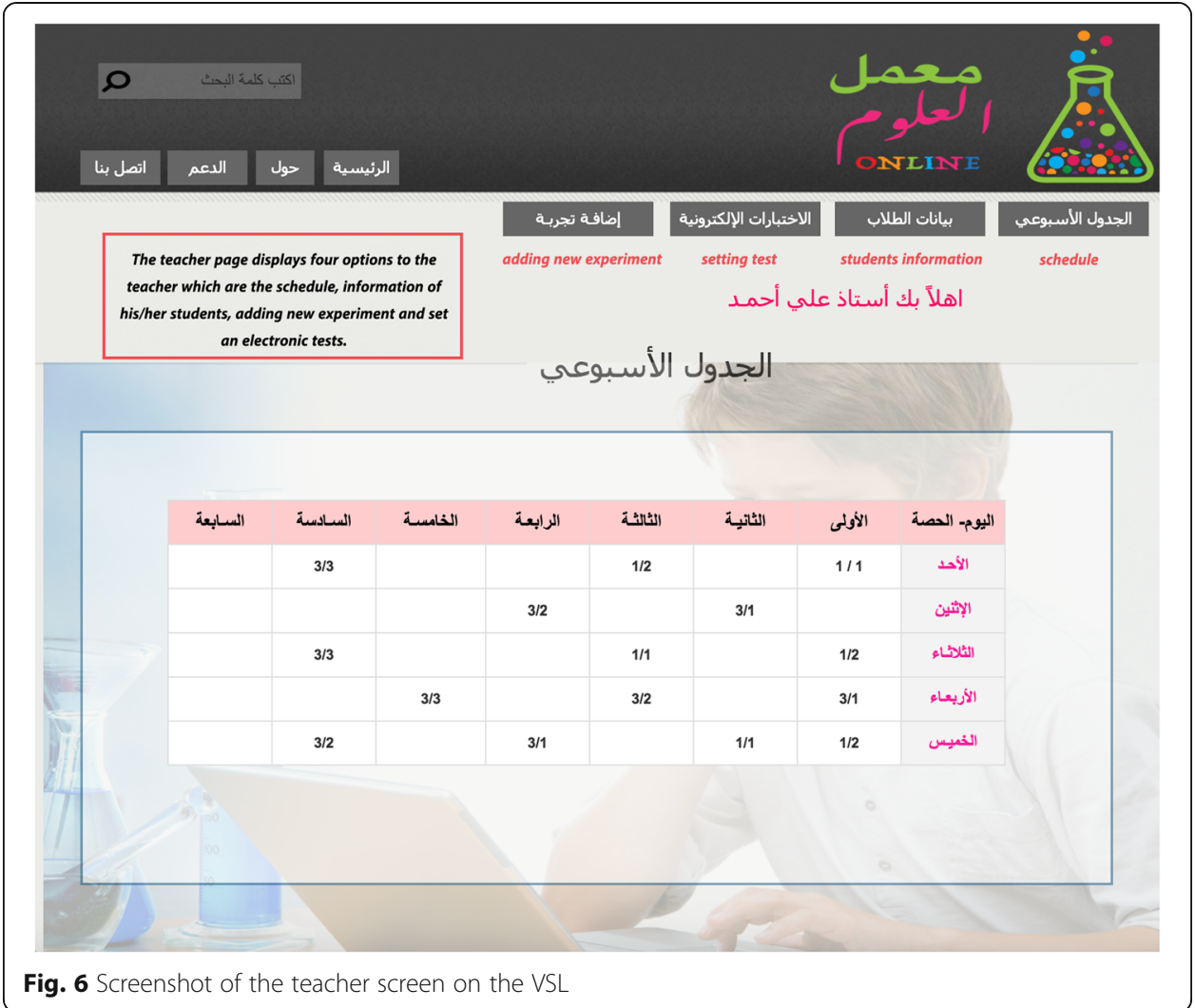

achievement by setting laboratory test and send it to the students as will be discussed later. The second function allows the creation of a new experiment by providing an interactive screen similar to the real lab environment that contains all the laboratory tools and materials needed (see Fig. 7). After completing this, the teacher will be able to send the new experiment to students and it will appear on the student screen. The electronic test screen represents the last function provided by the VSL system for teachers. Here, teachers can set a laboratory test and save it in the system. The screen will then show a drop-down menu of the test bank and show two options: display and modify the test or send the test to the student.

\section{Testing and results}

To evaluate the efficiency of using the VSL and to measure its differences compared to HOLs, a pre-test was conducted with five second-year middle school students from different schools in Jeddah. The students used different computers and were supervised by researchers. Before starting the computer test, the students were asked about their knowledge and understanding of the main concepts of certain science experiments that are taught to them in HOLs. The results showed that $60 \%$ of the students had difficulty understanding the essential objectives of the given experiments and only $40 \%$ understood the experiments well.

The students were then asked to conduct the same experiments individually using the VSL. Their experience of using the virtual environment when conducting the experiments was then assessed through a post-test. They have been asked about usability of VSL: ease of use the experiments' tools, clarity of the experiments' steps, navigating 


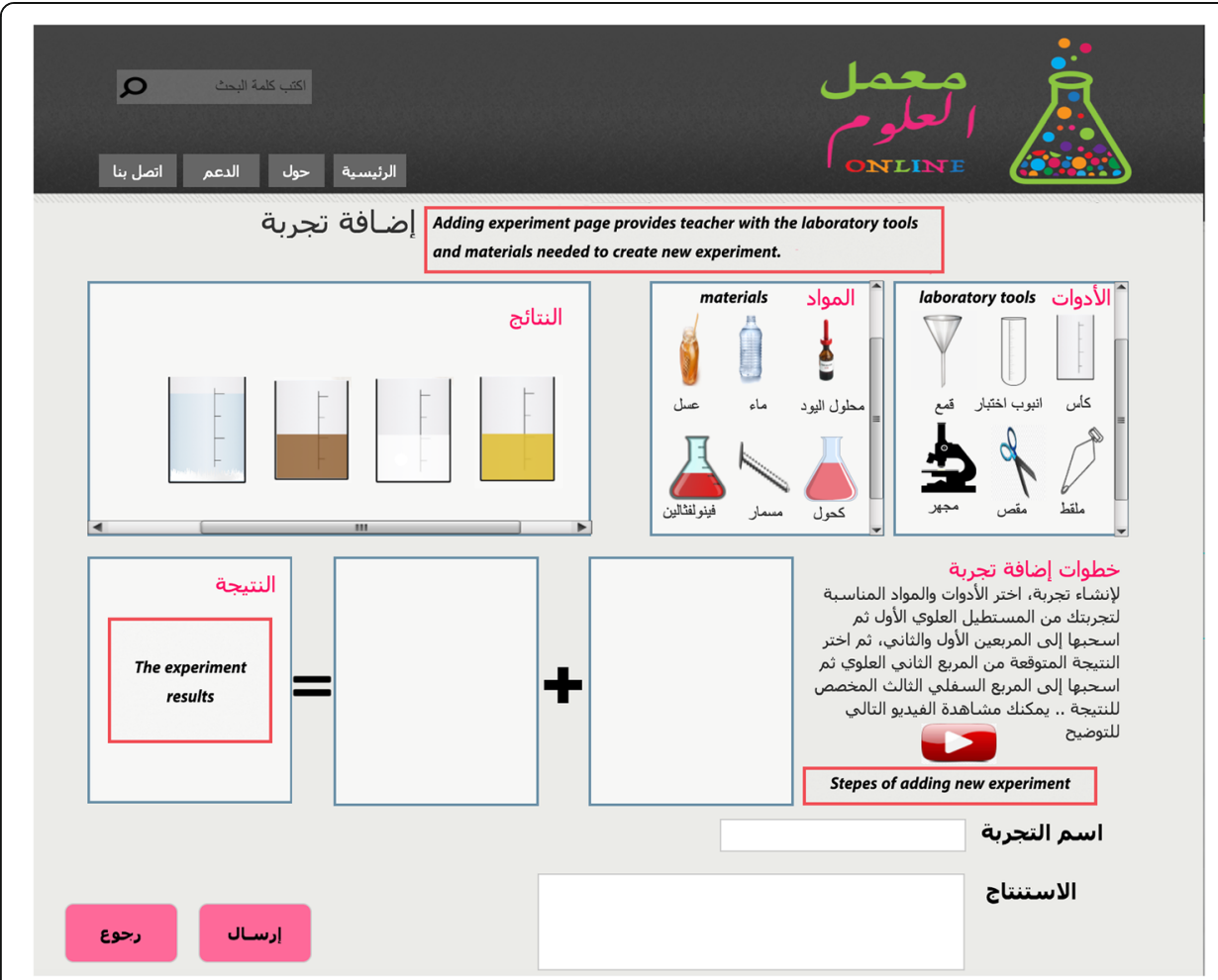

Fig. 7 Screenshot of the add experiment interface on the VSL

between the VSL's screens, and the interaction and enjoyment during the implementation of the experiment in the VSL.

And it was found that $80 \%$ of students had a good understanding of the practical experiments after performing them in the VSL. Furthermore, the students liked the interface design and did not report any difficulties in navigating between screens. Moreover, according to their answers, using the VSL was an exciting and satisfactory experience for the students.

\section{Discussion}

As (Babateen 2011) mentioned the importance of using the computer simulation's applications in improving the knowledge and learning of the science experiments. Also, VSL's results agreed with them in the obvious enhancement for students' understanding of the science experiments. The results indicate the positive impact of using the VSL on the students and demonstrate that there is a need for the VSL in the middle schools in Saudi Arabia.

The VSL could improve the learning environment and deliver information to the students more clearly. The students who used the VSL were able to understand the concept of experiments, their objectives, and the results. Using the visualizations that imitated experiments in HOLs and the ability to conduct the experiments individually also helped the students to understand and remember the information. The VSL can promote learning as fun as all the students were happy and enjoyed conducting the experiments. Also, they explored more experiments and learned more things. Moreover, the system is considered as a smart environment where it provides the students with 
adequate feedback during the learning process and enables the teacher to follow and assess the student's performance. Also, its planned to add more feature to make it smarter such as a personalization interface for each student and offering the teachers with recommendations for each student based on their performance records. However, there are some obstacles to applying the VSL in schools: (Afgan et al. 2015) teachers must be trained in how to use the VSL, (Alexiou et al. 2005) some teachers may refuse to use it and prefer using traditional methods, and (Ayesh 2004) some schools in small towns and villages cannot afford the computers and the equipment.

\section{Conclusions and future work}

Emerging technologies have successfully enhanced the learning and teaching process and support science education by providing an interactive learning environment that enables the students to participate and learn. VLs are one of the best ways to teach students and allow them to conduct experiments instead of simply viewing them. Moving from HOLs to VLs could also reduce costs and increase teaching efficiency. Moreover, teaching techniques should always be modern and flexible so they can keep up with evolving technologies. This can be achieved easily in Saudi Arabia by having VLs in all Saudi schools in the future and linking them with current e-learning systems, such as Noor and Clasera.

\section{Limitation of the research}

One of the limitations of VSL research was in the testing phase, because of pre-test existence, the results of the conducting the experiment using VSL may be affected by the pre-test. Also, the researchers, unfortunately, have not been able to test the system with a large number of students as desired because of time constraints. The testing and evaluation phase collided with final exams in Saudi schools. Hence, to have formal permission from schools in that period was difficult. Moreover, some structured interviews have been arranged with about six science teachers, but 4 of them did not cooperate because of either school policies or their time. The researchers believe that although the numbers aren't significant but this study still highlights the importance of the problem under study and provide a feasible solution that would be assessed further in future studies.

\section{Additional file}

Additional file 1: Questionnaire to measure the status of science labs in schools in Saudi Arabia. (DOCX 66 kb)

Abbreviations

HOL: Hands-on laboratories; VL: Virtual laboratories; VSL: Virtual Science Lab

Acknowledgements

The authors thank the science teachers and students who participated in the research for their efforts and commitment.

Availability of data and materials

The data analyzed during the study including the questionnaire, interviews, pre-test, and post-test are not publicly available but are available from the authors on request.

Authors' contributions

The first three authors are master students contributed equally to this project. Fourth author supervised the whole project, giving feedback and proofreading. All authors read and approved the final manuscript. 
Competing interests

The authors declare that they have no competing interests.

\section{Publisher's Note}

Springer Nature remains neutral with regard to jurisdictional claims in published maps and institutional affiliations.

\section{Author details}

${ }^{1}$ Information Systems Department, Faculty of Science and Computer Engineering, Taibah University, Yanbu, Saudi Arabia. ${ }^{2}$ Information Systems Department, Faculty of Computing \& Information Technology, King Abdulaziz University, Jeddah, Saudi Arabia.

Received: 8 June 2018 Accepted: 7 September 2018

Published online: 14 September 2018

References

Afgan, E., Sloggett, C., Goonasekera, N., Makunin, I., Benson, D., Crowe, M., .. Horst, R. (2015). Genomics virtual laboratory: A practical bioinformatics workbench for the cloud. PLoS One, 10(10), e0140829

A. Alexiou, C. Bouras, E. Giannaka, in Technology Enhanced Learning. Virtual Laboratories in Education (Springer, Boston, MA, 2005), pp. 19-28

S. Alshahry, The effect of using the virtual laboratory (crocodile) in developing the skills of integrative science in chemistry course for the secondary students in Riyadh City. Pedagogue World 17(55), 123-175 (2016)

Ayesh, Z. (2004). Methods of Teaching Science. Jordan: Dar Al Shorouk for Publishing and Distribution.

H.M. Babateen, The role of virtual lab in science education. 5th International Conference on distance learning and education (2011), pp. 100-104

B. Bortnik, N. Stozhko, I. Pervukhina, A. Tchernysheva, G. Belysheva, Effect of virtual analytical chemistry laboratory on enhancing student research skills and practices. Res. Learn. Technol. 25 (2017). https://doi.org/10.25304/rlt.v25.1968

O.C. Falode, S.A. Onasanya, Teaching and learning efficacy of virtual laboratory package on selected nigerian secondary school physics concepts. Bulg. J. Chem. Educ. 24(4), 572-283 (2015)

H.E. Keller, E.E. Keller, Making Real Virtual Labs. Sci. Educ. Rev. 4(1), 2-11 (2005)

D. Kennepohl, Accessible elements: Teaching science online and at a distance, by D. Kennepohl \& L. Shaw (Eds) freely downloadable from. Phys. Teach. 49(1), 63-63 (2011)

M. Meccawy, Raising a programmer: Teaching Saudi children how to code. Int. J. Educ. Technol. 4(2), 56-65 (2017) Retrieved from https://educationaltechnology.net/ijet/index.php/ijet/article/view/25

Salehi, A., Jimenez-Berni, J., Deery, D. M., Palmer, D., Holland, E., Rozas-Larraondo, P.. . . Furbank, R. T. (2015). SensorDB: a virtual laboratory for the integration, visualization and analysis of varied biological sensor data. Plant Methods, 11(1), 53

I. Sommerville, Software engineering, 9th edn. (Addison-Wesley, New York, 2010)

K.-t. Sun, Y.-c. Lin, C.-j. Yu, A study on learning effect among different learning styles in a web-based lab of science for elementary school students. Comput. Educ. 50(4), 1411-1422 (2008)

E.E. Toth, Analyzing "real-world" anomalous data after experimentation with a virtual laboratory. Educ. Technol. Res. Dev. 64(1), 157-173 (2016)

C. Tuysuz, The effect of the virtual laboratory on Students' achievement and attitude in chemistry. Int. Online J. Educ. Sci. 2(1), 37 e53 (2010)

M.M. Waldrop, The virtual lab. Nature 499(7458), 268 (2013)

A. Widodo, R.A. Maria, A. Fitriani, Constructivist learning environment during virtual and real laboratory activities. Biosaintifika 9(1), 11-18 (2017)

\section{Submit your manuscript to a SpringerOpen ${ }^{\circ}$ journal and benefit from:}

- Convenient online submission

- Rigorous peer review

- Open access: articles freely available online

- High visibility within the field

- Retaining the copyright to your article

Submit your next manuscript at $\mathbf{s p r i n g e r o p e n . c o m ~}$ 